\title{
Weight Analysis based on ANP and QFD in Software Quality Evaluation
}

\author{
Kewen Li*, Yu Zhang, Wenying Liu \\ School of Computer and Communication Engineering,China University of Petroleum, Qingdao, Shandong, 266580, China
}

Received: 12 Apr. 2013, Revised: 13 Aug. 2013, Accepted: 15 Aug. 2013

Published online: 1 Mar. 2014

\begin{abstract}
Over the past two decades, considerable efforts focused on improving software quality to satisfy the customers needs in software industry, but it is hard to deal with the customers needs for its vague and inexact characteristic. In order to evaluate software quality accurately and comprehensively, the weights of customers needs and the weights of technical attributes of the software are determined by ANP and QFD in the paper. An illustrated example is presented to show the application of the proposed model, and the results show that the weights of product characteristics and the customers needs in HoQ (House of Quality) analyzed by ANP can make software quality more accurate and comprehensive in software quality evaluation.
\end{abstract}

Keywords: software quality, quality function deployment, analytic network process

\section{Introduction}

With the development of economy, a large number of software products widely used in all aspects of life have been produced. However, the satisfaction of customers to these software products could not be guaranteed very well so far, which easily lead to poor quality of these software products. It is important to study the method of software quality evaluation to make sure that the products better meet the customers needs.

Software products are very different from other products. One important difference we can not ignore is that software products are often based on a user's specific needs. Each software is produced by different demands put forward by customers. For example, military applications have more requirements for security, but software for the aerospace, real-time should belong to high reliability. It is important to make clear the customers needs and the relative importance of each demand before programming. The weight of each customers needs should be calculated quantitatively if you want to satisfy the customer. The so-called weight, is a relative concept, the weight of an indicator is the relative importance in the overall evaluation. In this paper, we mainly study the weight of the customers needs and the weight of technical attributes of the software.
Many scholars have made a lot of researches for the determination of the weight. In China, some early researchers usually used the expert scoring method to determine the target weight, which mainly made use of expert experience to estimate the relative importance of indicators. However, the expert scoring method has many disadvantages which easily lead to large errors because of its strong subjectivity. Many scholars have applied other methods to determining the weight of indicators, and a lot of theories and methods have been studied in this field. For example, some scholars have applied principal component analysis to analyzing the weights which adopts the theory of dimensionality reduction to cut the original interrelated indicators integrated into fewer new indicators, which contain the main information of original indicators[1]. It could reduce the computational complexity of the problem by the principal component analysis method to analyze the weights of indicators when it comes to a small problem, but the calculation becomes much complicated when the scale of the problem gets larger. Many scholars analyzed the indicators weight with the rough set theory which focuses on the situation whose information is not complete[2]. At present, one of the most popular methods is AHP, which decomposes elements into three layers: objectives, guidelines, and properties and take qualitative analysis on this basis. Some researches combined AHP with the

\footnotetext{
*Corresponding author e-mail: likw@upc.edu.cn
} 


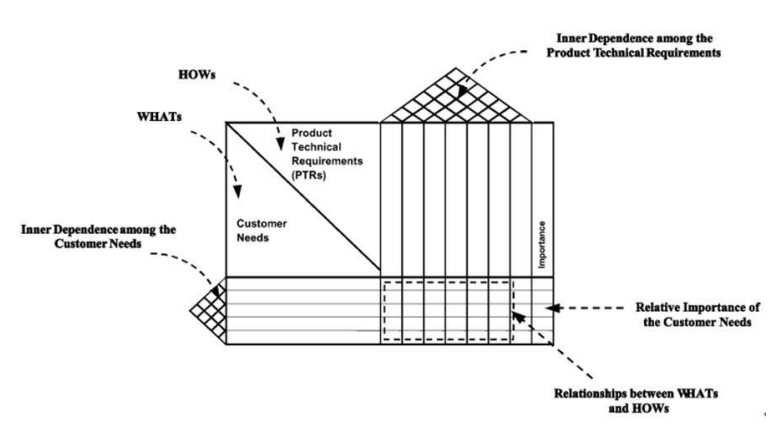

Fig. 1: House of quality

quality of house to determine the weight of the indicators. However, AHP decision-making is only emphasized one-way relationship between the levels, which focuses on the impact between two levels, but in a lot of complex problems, the elements in the same layer also could interact each other[3,9]. For example, the interaction between the properties of software product can not be ignored in software quality evaluation. In this paper, we propose the use of the analytic network process (ANP) to incorporate the inner dependence into customer needs and properties in HoQ(Quality of House). ANP enables us to take the degree of interdependences between customers needs and properties by means of AHP into consideration, which better express the "voice of the user" $[4,5,12]$.

\section{Quality Function Deployment (QFD) and literature review}

Quality Function Deployment (QFD) is a key tool for application of concurrent engineering and implementing total quality management, which emphasizes providing a coherent response to customers needs in the process of product planning, product design, process planning, and production planning. In other words, QFD can be seen as a set of planning tools, which help introducing new or improved products faster to market by focusing on the customers satisfaction.

The basic concept of QFD is to translate the needs of customers (CNs), in other words, voice of customer, into product technical requirements (PTRs) or engineering characteristics, and subsequently into parts characteristics, process plans, and production requirements related to its manufacture. Each translation uses a chart, called House of Quality(HoQ)[3]. The components of HoQ are displayed in Fig. 1.

(1) Customers needs (WHATs). This part is called the voice of the customer or customers requirements. It is the initial input for the HoQ and points at to the product characteristics which should be paid attention to. Customer needs, usually collected by focus groups or individual interviews, should be expressed in customers own phrases. Preserving customers own words usually causes problems during the phase of translation and interpretation since they are usually too general and/or detailed to be directly used as customer needs. A number of approaches are used in order to overcome this problem. Initially the words are collected, and then they are organized to form a tree-like hierarchy usually with three or four levels. Those at the appropriate level are chosen as the final customer needs. Affinity diagram, which is a method used to gather large amounts of qualitative data and to organize them into subgroups based on the similarities between them, can be used for this purpose. Cluster analysis can also be used to form and structure customer needs.

(2) PTRs (HOWs). PTRs are also known as product features or product attributes. They can also be developed using the affinity diagram and tree diagram. They describe the product in the language of the engineer. Therefore, they are sometimes referred to as the voice of the company. The PTRs are used to determine how well the company satisfies the customer needs. Customer needs tell the company what to do while the PTRs tell how to do it.

(3) Relative importance of the customer needs. Because the collected and organized data from the customer usually contain too many needs to deal with simultaneously, the company have to trade off one benefit against another, and work on the most important needs while disregarding relatively unimportant ones. In this manner, customers are surveyed using 5-, 7- or 9-point scales.

(4) Relationships between WHATs and HOWs. The relationship matrix indicates how much each PTR affects each customer need. The relations can either be presented in numbers or symbols. In this paper, we will use numbers to denote the relationship between WHATs and HOWs.

(5) Inner dependence among the customer needs. In general, customer needs have inner dependence among them. Some of them will support each other whereas others will adversely affect the achievement of others. These supporting and conflicting needs can be identified by a correlation matrix emphasizing necessary trade-offs.

(6) Inner dependence among the PTRs. The HoQs roof matrix is used to specify the various PTRs that have to be improved collaterally, and provide a basis to calculate to what extent a change in one feature will affect other features. A desirable change in one feature may result in a negative effect on another feature. This correlation facilitates the necessary engineering impacts and trade-offs. The HoQ is usually built by using the seven elements mentioned above. With its design-oriented nature, the HoQ serves not only as a valuable resource for designers but also as a way to summarize and convert feedback from customers into information for engineers. In addition, marketing can benefit from it since it is based on the voice of customer, and upper management can use it to develop strategic opportunities. Hence, the HoQ strengthens vertical and horizontal communications. Once 


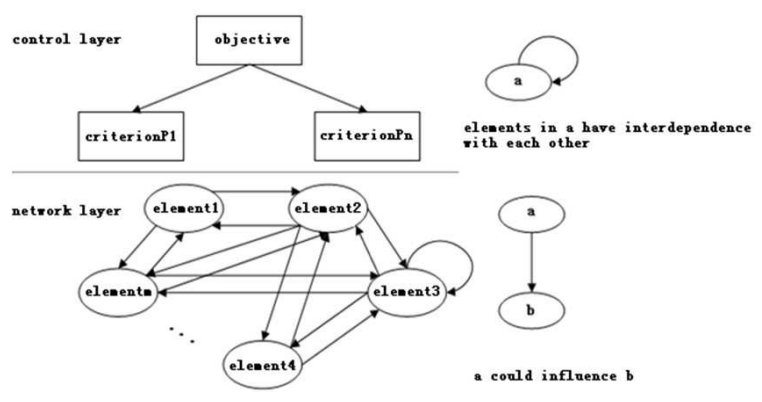

Fig. 2: Typical structure of ANP

having identified critical PTRs that demand change, they will be driven to the next matrix as WHATs to identify the critical parts characteristics.

\section{The analytic network process (ANP) and its usage in QFD}

Analytic network process is a widely used multi-attribute decision-making approach, which expands the network relationships of elements in AHP to the network relationships to analyze problems. AHP is a special case of analytic network process. The core of AHP is to make level for the system and only takes the dominant role from the upper level to the lower level into consideration, the elements on the same hierarchy is considered to be independent of each other. However, in many cases, the relationship between elements of the system is not a simple hierarchy, but a complex network of relationships, so AHP is not suitable to analyze the complex network relationships [4, 6, 8].

The decision-making level in AHP is an unidirectional hierarchy, but analytic network process can take the inter-relationship into account between decision-making level and elements, and there is no strict hierarchy, shown in Fig 2, nodes representing the system components, arrows indicating the relationship between them, the arrows indicating the direction of dependency.

The method of determining the value of relative importance of elements in analytic network process is similar to level analysis, which is by the way of comparing. It applies the range standard of 1-9, in which 1 represents the same value of importance between two elements, and 9 represents one element is far more important than the other one. If $a_{i j}$ represents the relative importance from the $i$ th element to the $j$ th element,

$$
a_{j i}=\frac{1}{a_{i j}}
$$

represents the relative importance from the $j$ th element to the $i$ th element $[7,11,13]$.

Generally speaking, ANP is composed of two stages. The first stage is the composition of network, and the

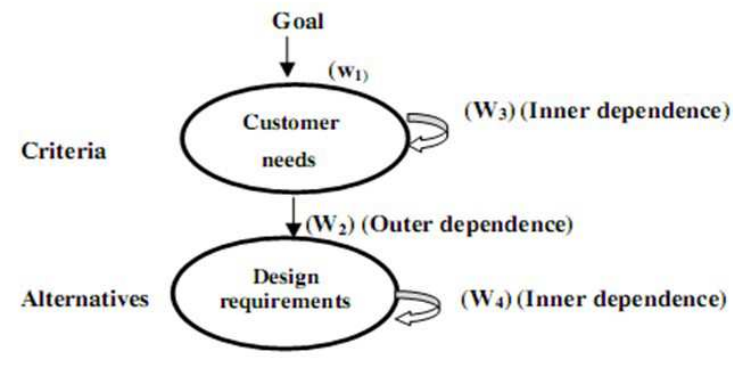

Fig. 3: The network relationship in QFD

other is to calculate the priority value of each element. Constructing the architecture of network should take the relationships of all elements into consideration. Super-matrix is used to represent the interaction of elements. A super- matrix which has three hierarchies is shown as follows:

$$
W=\begin{aligned}
& \text { Goal }(G) \\
& \text { Criteria }(C) \\
& \text { Alternative }(A)
\end{aligned}\left(\begin{array}{ccc}
G & C & A \\
0 & 0 & 0 \\
w_{21} & 0 & 0 \\
0 & W_{32} & I
\end{array}\right)
$$

The Vector $w_{21}$ represents the influence from target level to the criterion level, and matrix $W_{32}$ represents the influence from criterion level to each attribute element. I is unit matrix $[4,10]$.

\section{The decision methodology}

The decision algorithm addresses the problem of selecting the PTRs which are focused on in the design process considering the predetermined goals. The algorithm can be divided into two major phases. In the first phase, the HoQ is constructed by using the ANP approach, and in the second phase, we determine the set of PTRs that the design team needs to concentrate on based ANP.

The network relationships in QFD is implemented by adding the internal links between elements. In the structure of QFD, customer needs (CNs) corresponds to the criteria in ANP, and there are interdependent relationships between customer needs. The network representation in QFD model is based on the structure of a hierarchy with inner dependencies within components and no feedback. In this situation, the CNs correspond to the alternatives, which have inner dependencies within themselves, as shown in Fig.3:

The first step of the network representation in QFD model is the identification of the CNs and PTRs. Then, the importance of the $\mathrm{CNs}$ is determined, which corresponds to the matrix manipulation concept of the ANP in the first step. Next, the body of the house will be filled through comparing the PTRs with respect to each 
CN. Finally, the interdependent priorities of the PTRs will be obtained by analyzing dependencies among the CNs and PTRs. The supermatrix representation of the QFD model used in this study is as follows:

$$
W=\begin{aligned}
& \text { Goal }(G) \\
& \text { CustomerNeeds }(\text { CNs }) \\
& \text { ProductTechnicalRequirements }
\end{aligned} \quad\left(\begin{array}{ccc}
G & C N s & P T R s \\
0 & 0 & 0 \\
w_{1} & W_{3} & 0 \\
0 & W_{2} & W_{4}
\end{array}\right)
$$

where $W_{1}$ is a vector on the CNs that represents the impact of the goal, namely manufacturing a product that satisfies the customer. $W_{2}$ is a matrix that denotes the impact of the CNs on each of the PTRs. $W_{3}$ and $W_{4}$ are the matrices that represent the inner dependence of the $\mathrm{CNs}$ and the inner dependence of the PTRs respectively[3,4, $14,15]$

The evaluation algorithm steps for determining the overall priorities of the PTRs as follows:

Step 1. Identifying CNs and determining the PTRs matching the CNs.

Step 2. Determining the importance degrees of CNs with linguistic data by assuming that there is no dependence among the CNs: Calculation of $W_{1}$.

Step 3. Determining the importance degrees of PTRs with respect to each $\mathrm{CN}$ with linguistic data by assuming that there is no dependence among the PTRs: Calculation of $W_{2}$.

Step 4. Determining the inner dependency matrix of the CNs with respect to each $\mathrm{CN}$ with linguistic data by utilizing the schematic representation of inner dependence among CNs: Calculation of $W_{3}$.

Step 5. Determining the inner dependency matrix of the PTRs with respect to each PTR with linguistic data by utilizing the schematic representation of inner dependence among PTRs: Calculation of $W_{4}$.

Step 6. Determining the interdependent priorities of the CNs: Calculation of $w_{c}=W_{3} * w_{1}$.

Step 7. Determining the interdependent priorities of the PTRs: Calculation of $w_{A}=W_{2} * W_{4}$.

Step 8. Determining the overall priorities of the PTRs: Calculation of $w^{A N P}=w_{c}{ }^{*} w_{A}$.

\section{Case study-empirical application}

Search engines are widely used in internet as a tool of information search. In the paper the methods presented in previous will be used to analysis demand weight and technology weight of this information search. The house of quality used in this example is showed in Fig.4 [9]:

Step 1:The example including five user demands which are expandability, reliability, speed, correctness and usability via the demand analysis. The eight software feature that may impact the user demand respectively is response time, database size, accuracy, language number, unique hits, dead links, update time, format number.

Step 2:In this step, assuming that there is no any dependence among each user demand and the initial

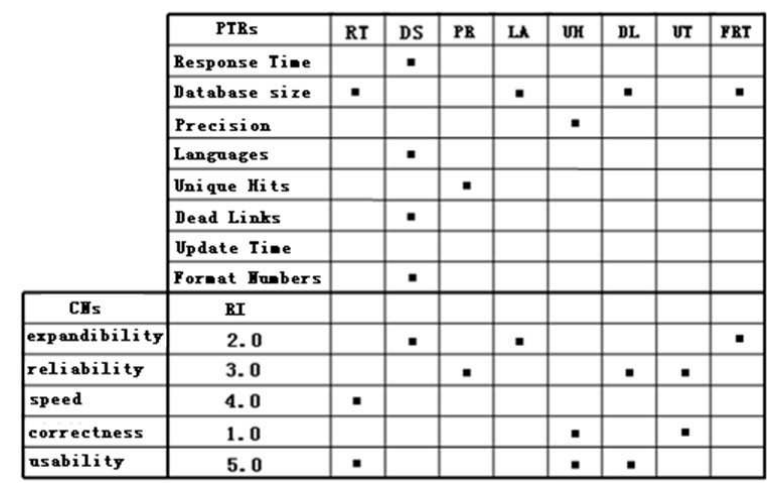

Fig. 4: The HoQ of Search engine

Table 1: Relative importance of the product characteristic relative to reliability

\begin{tabular}{|lllll|}
\hline reliability & precision & dead links & update time & $\begin{array}{l}\text { relative } \\
\text { importance }\end{array}$ \\
\hline precision & 1 & 9 & 3 & 0.719 \\
\hline dead links & $1 / 9$ & 1 & 3 & 0.166 \\
\hline update time & $1 / 3$ & $1 / 3$ & 1 & 0.115 \\
\hline
\end{tabular}

relative importance of user demand can be obtained through the questionnaire for the users. In the example, the initial relative importance of user demand is obtained through the questionnaire $\mathrm{C}$ Which need is more important and how important it is in the design of this search engines, normalize the data and get the vector quantity $w_{1}$.

$$
W=\left(\begin{array}{c}
\text { expandability } \\
\text { reliability } \\
\text { speed } \\
\text { correctness } \\
\text { usability }
\end{array}\right)=\left(\begin{array}{c}
0.133 \\
0.2 \\
0.267 \\
0.067 \\
0.333
\end{array}\right)
$$

Step 3: Assuming that there is no any dependence among each product characteristic in the design of this search engines and acquiring the relative importance of the product characteristic relative to the user demand through the paired comparison. For example, for the reliability in the user demand, the relative importance of the product characteristic can be obtained through the questionnaire $\mathrm{Cwhich}$ is more important for reliability and accuracy relative to dead links and how important it is, which is showed in table 1 . The same method can be used to obtain the relative importance of the other product characteristic relative to the user demand and then get the matrix $W_{2}$, which is showed in table 2 .

Step 4: Analyzing the dependent relation among each user demand, which is showed in Fig.5. The relative importance of each user demand relative to the other user demand can be determined through the Paired comparison. For example, for the correctness in the user demand, the relative importance of the product characteristic can be determined through the 
Table 2: Relative importance of the product characteristic relative to each user demand

\begin{tabular}{|l|l|l|l|l|l|}
\hline$W_{2}$ & expandabilit & reliability & speed & correctness & usability \\
\hline $\begin{array}{l}\text { response } \\
\text { time }\end{array}$ & 0.000 & 0.000 & 1.000 & 0.000 & 0.375 \\
\hline $\begin{array}{l}\text { database } \\
\text { size }\end{array}$ & 0.600 & 0.000 & 0.000 & 0.000 & 0.000 \\
\hline precision & 0.000 & 0.719 & 0.000 & 0.719 & 0.000 \\
\hline $\begin{array}{l}\text { language } \\
\text { number }\end{array}$ & 0.200 & 0.000 & 0.000 & 0.000 & 0.000 \\
\hline $\begin{array}{l}\text { unique } \\
\text { hits }\end{array}$ & 0.000 & 0.000 & 0.000 & 0.166 & 0.125 \\
\hline $\begin{array}{l}\text { dead } \\
\text { links }\end{array}$ & 0.000 & 0.166 & 0.000 & 0.000 & 0.125 \\
\hline $\begin{array}{l}\text { update } \\
\text { time }\end{array}$ & 0.000 & 0.115 & 0.000 & 0.115 & 0.000 \\
\hline $\begin{array}{l}\text { format } \\
\text { number }\end{array}$ & 0.200 & 0.000 & 0.000 & 0.000 & 0.375 \\
\hline
\end{tabular}

Table 3: Relative importance of each user demand relative to correctness

\begin{tabular}{|l|l|l|l|l|}
\hline correctness & reliability & usability & correctness & $\begin{array}{l}\text { relative } \\
\text { importance }\end{array}$ \\
\hline reliability & 1 & $3 / 5$ & $3 / 4$ & 0.223 \\
\hline usability & $5 / 3$ & 1 & 5 & 0.59 \\
\hline $\begin{array}{l}\text { relative } \\
\text { importance }\end{array}$ & $4 / 3$ & $1 / 5$ & 1 & 0.187 \\
\hline
\end{tabular}

Table 4: Relative importance among each user demand

\begin{tabular}{|l|l|l|l|l|l|}
\hline$W_{3}$ & expandability & reliability & speed & correctness & usability \\
\hline expandability & 0.286 & 0 & 0 & 0 & 0.133 \\
\hline reliability & 0 & 0.333 & 0 & 0.223 & 0.2 \\
\hline speed & 0 & 0 & 0.444 & 0 & 0.267 \\
\hline correctness & 0 & 0.111 & 0 & 0.187 & 0.067 \\
\hline usability & 0.714 & 0.556 & 0.556 & 0.59 & 0.333 \\
\hline
\end{tabular}

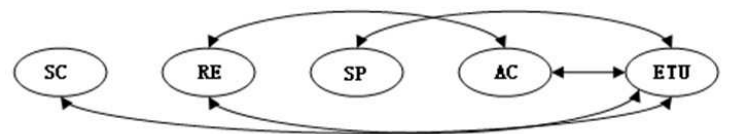

Fig. 5: codependent relations among each user demand

questionnaire Cwhich is more important for response time relative to usability and how important it is, which is showed in table 3 . The same method can be used to obtain the relative importance of the other user demand and then get the matrix $W_{3}$, which is showed in table 4 .

Step 5: In this step the relative importance among the product characteristic is discussed and the dependent relation of the product characteristic is analyzed, which is showed in Fig.6. We also determine the relative importance of the product characteristic through the method of Paired comparison. For example, for the database size in the product characteristic, we determine the relative importance of the product characteristic through the questionnaire Cwhich is more important for database size with response time relative to language number and how important it is, which is showed in table 5 . We can to obtain the relative importance of the other
Table 5: Relative importance of the product characteristic relative to database size

\begin{tabular}{|l|l|l|l|l|l|l|}
\hline & $\begin{array}{l}\text { response } \\
\text { time }\end{array}$ & $\begin{array}{l}\text { language } \\
\text { number }\end{array}$ & $\begin{array}{l}\text { dead } \\
\text { links }\end{array}$ & $\begin{array}{l}\text { format } \\
\text { number }\end{array}$ & $\begin{array}{l}\text { database } \\
\text { size }\end{array}$ & $\begin{array}{l}\text { relative } \\
\text { importance } \\
\text { number }\end{array}$ \\
\hline $\begin{array}{l}\text { response } \\
\text { time }\end{array}$ & 1 & $4.5 / 2$ & $4.5 / 4$ & $4.5 / 3.5$ & $4.5 / 2$ & 0.281 \\
\hline $\begin{array}{l}\text { language } \\
\text { number }\end{array}$ & $2 / 4.5$ & 1 & $1 / 2$ & $2 / 3.5$ & 1 & 0.125 \\
\hline $\begin{array}{l}\text { dead } \\
\text { links }\end{array}$ & $4 / 4.5$ & 2 & 1 & $4 / 3.5$ & 2 & 0.25 \\
\hline $\begin{array}{l}\text { format } \\
\text { number }\end{array}$ & $3.5 / 4.5$ & $3.5 / 2$ & $3.5 / 4$ & 1 & $3.5 / 2$ & 0.219 \\
\hline $\begin{array}{l}\text { database } \\
\text { size }\end{array}$ & $2 / 4.5$ & 1 & $1 / 2$ & $2 / 3.5$ & 1 & 0.125 \\
\hline
\end{tabular}

Table 6: Relative importance among the characters of the product

\begin{tabular}{|l|l|l|l|l|l|l|l|l|}
\hline$W_{4}$ & $\begin{array}{l}\text { database } \\
\text { size }\end{array}$ & $\begin{array}{l}\text { response } \\
\text { time }\end{array}$ & accuracy & $\begin{array}{l}\text { language } \\
\text { number }\end{array}$ & $\begin{array}{l}\text { special } \\
\text { click }\end{array}$ & $\begin{array}{l}\text { dead } \\
\text { links }\end{array}$ & $\begin{array}{l}\text { update } \\
\text { time }\end{array}$ & $\begin{array}{l}\text { format } \\
\text { number }\end{array}$ \\
\hline $\begin{array}{l}\text { database } \\
\text { size }\end{array}$ & 0.692 & 0.281 & 0 & 0 & 0 & 0 & 0 & 0 \\
\hline $\begin{array}{l}\text { response } \\
\text { time }\end{array}$ & 0.308 & 0.125 & 0 & 0.5 & 0 & 0.333 & 0 & 0.364 \\
\hline accuracy & 0 & 0 & 0.4 & 0 & 0.4 & 0 & 0 & 0 \\
\hline $\begin{array}{l}\text { language } \\
\text { number }\end{array}$ & 0 & 0.125 & 0 & 0.5 & 0 & 0 & 0 & 0 \\
\hline $\begin{array}{l}\text { unique } \\
\text { hits }\end{array}$ & 0 & 0 & 0.6 & 0 & 0.6 & 0 & 0 & 0 \\
\hline $\begin{array}{l}\text { dead } \\
\text { links }\end{array}$ & 0 & 0.25 & 0 & 0 & 0 & 0.667 & 0 & 0 \\
\hline $\begin{array}{l}\text { update } \\
\text { time }\end{array}$ & 0 & 0 & 0 & 0 & 0 & 0 & 1 & 0 \\
\hline $\begin{array}{l}\text { format } \\
\text { number }\end{array}$ & 0 & 0.219 & 0 & 0 & 0 & 0 & 0 & 0.636 \\
\hline
\end{tabular}

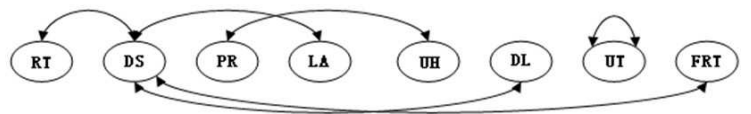

Fig. 6: Codependent relations among the product characteristic

user demand by the same method and then get the matrix $W_{4}$, which is showed in table 6 .

Step 6: The initial weight of user demand and the relative importance among each user demand have been obtained in the previous step. The weight vector quantity $w_{c}$ in the consideration of the dependent relation will be worked out in this step.

$$
w_{c}=W_{3} * w_{1}=\left(\begin{array}{c}
0.082 \\
0.148 \\
0.208 \\
0.057 \\
0.505
\end{array}\right)
$$

Step 7: Working out the dependent matrix $W_{A}$ of the product characteristic through the product characteristic relative to demand weight matrix which each user needed and the relative importance matrix among the product characteristic. 


$$
W_{A}=W_{4} * W_{2}=\left(\begin{array}{ccccc}
0.169 & 0 & 0.692 & 0 & 0.26 \\
0.248 & 0.055 & 0.308 & 0 & 0.294 \\
0 & 0.288 & 0 & 0.354 & 0.05 \\
0.175 & 0 & 0 & 0 & 0 \\
0 & 0.431 & 0 & 0.531 & 0.075 \\
0.15 & 0.111 & 0 & 0 & 0.083 \\
0 & 0.115 & 0 & 0.115 & 0 \\
0.259 & 0 & 0 & 0 & 0.239
\end{array}\right)
$$

Step 8: The total weigh number $W^{A N P}$ of the product characteristic will be obtained, which can sufficiently show the correlation between the user demand of product in quality house and the product characteristic.

$$
W^{A N P}=W_{A} * w_{c}=\left(\begin{array}{c}
\text { responsetime } \\
\text { databasesize } \\
\text { accuracy } \\
\text { languagenumber } \\
\text { uniquehits } \\
\text { deadlinks } \\
\text { updatetime } \\
\text { formatnumber }
\end{array}\right)=\left(\begin{array}{c}
0.289 \\
0.241 \\
0.088 \\
0.144 \\
0.132 \\
0.071 \\
0.024 \\
0.142
\end{array}\right)
$$

\section{Conclusions}

In this paper, the methods to determine the weight of customer needs and the weight of technical attributes of the software with ANP used in QFD have been studied. It is more accurate and comprehensive that the weight of the product characteristics and the user needs in HoQ (House of Quality) are analyzed by ANP, which can effectively improve the accuracy of software quality evaluation by applying this method to the software quality evaluation.

The authors are grateful to the anonymous referee for a careful checking of the details and for helpful comments that improved this paper.

\section{References}

[1] Luo zhi zhong, Zhang feng yan., Application of principal component analysis method in calculating the weights of the indexes of the highway nodes' importance. Journal of Transportation Systems Engineering and Information Technology, 5, (2005).

[2] Peng Long, Zhou Ming., The method of calculating the weight and its application based on fuzzy rough set theory.Journal of Sichuan university of science and engineering, 22, (2009).

[3] E. Ertugrul Karsak, Sevin Sozer, S.Emre Alptekin.,Product planning in quality function deployment using a combined analytic network process and goal programming approach. Computers and Industrial Engineering, 44, 171-190 (2002).

[4] Zeynep Sener, E. Ertugrul Karsak., A fuzzy regression and optimization approach for setting target levels in software quality function deployment. Software Qual J, 18, 323-339 (2010).
[5] C. K. Kwong, Y. Chen, H.Bai, D. S. K. Chan., A methodology of determining aggregated importance of engineering characteristics in QFD. Computers and Industrial Engineering, 53, 667-679 (2007).

[6] El-Gayar, O. F. Leung, P. S., A multiple criteria decision making framework for regional aquaculture development.European Journal of Operational Research, 133, 462-482 (2001).

[7] Lee, J. W, Kim, S. H., Using analytic network process and goal programming for interdependent information system project selection. Computers and Operations Research, 27, 367-382 (2000).

[8] Chang Che-Wei, Wu Cheng-Ru, Lin Hung-Lung., Integrating fuzzy theory and hierarchy concepts to evaluate software quality. Software Qual J, 16, 263-276 (2008).

[9] Armacost, R. L., Componation, P. J., Mullens, M. A., Swart, W. W., An AHP framework for prioritizing customer requirements in QFD: An industrialized housing application. IIE Transactions, 26, 72-79 (1994).

[10] Erol, I., Ferrell, W. G., A methodology for selection problems with multiple, conflicting objectives and both qualitative and quantitative criteria. International Journal of Production Economics, 86, 187-199 (2003).

[11] Kahraman, C., Cebeci, U., Ruan, D., Multi-attribute comparison of catering service companies using fuzzy AHP: The case of Turkey. International Journal of Production Economics, 87, 171-184 (2004).

[12] Kwong, C. K., Bai, H., Determining the importance weights for the customer requirements in QFD using a fuzzy AHP with an extent analysis approach. IIE Transactions, 35, 619626 (2003).

[13] Shin-ichi Ohnishi, Takahiro Yamanoi and Hideyuki Imai., A Kind of Fuzzy Weights Representation for Inner Dependence AHP.IEEE (2010).

[14] Park, T., Kim, K.. Determination of an optimal set of design requirements using house of quality. Journal of Operations Management, 16, 569-581 (1998).

[15] Badri, M. A. Combining the analytic hierarchy process and goal programming for global facility locationCallocation problem. International Journal of Production Economics, 62, 237-248 (1999).

Kewen $\mathbf{L i}$ received his $\mathrm{PhD}$ degree in Computer Science and technology from Tianjing University. His research interests include Computational Intelligence and Application, Software Engineering, especially in Software Quality Evaluation, Software Defect Prediction, and Process Improvement.

Yu Zhang received her Master's degree in Software Engineering from China University of Petroleum. Her research interests include Software Quality Evaluation, Software Defect Prediction, and Process Improvement.

Wenying Liu received her Master's degree in Computer Science and technology from China University of Petroleum. Her research interests include Computational Intelligence and Application, Computer System Architecture, and Data Mining. 